\title{
The Effect of Systematic Error in Forced Oscillation Testing
}

\author{
Brianne Y. Williams ${ }^{1}$ \\ The Aerospace Corporation, El Segundo, CA 90245 \\ Drew Landman ${ }^{2}$, and Isaac L. Flory IV ${ }^{3}$ \\ Old Dominion University, Norfolk, VA 23529 \\ and \\ Patrick C. Murphy ${ }^{4}$ \\ NASA Langley Research Center, Hampton, VA 23681
}

One of the fundamental problems in flight dynamics is the formulation of aerodynamic forces and moments acting on an aircraft in arbitrary motion. Classically, conventional stability derivatives are used for the representation of aerodynamic loads in the aircraft equations of motion. However, for modern aircraft with highly nonlinear and unsteady aerodynamic characteristics undergoing maneuvers at high angle of attack and/or angular rates the conventional stability derivative model is no longer valid. Attempts to formulate aerodynamic model equations with unsteady terms are based on several different wind tunnel techniques: for example, captive, wind tunnel single degree-of-freedom, and wind tunnel free-flying techniques. One of the most common techniques is forced oscillation testing. However, the forced oscillation testing method does not address the systematic and systematic correlation errors from the test apparatus that cause inconsistencies in the measured oscillatory stability derivatives. The primary objective of this study is to identify the possible sources and magnitude of systematic error in representative dynamic test apparatuses. Sensitivities of the longitudinal stability derivatives to systematic errors are computed, using a high fidelity simulation of a forced oscillation test rig, and assessed using both Design of Experiments and Monte Carlo methods.

$\begin{array}{ll} & \\ B & =\text { Nomping constant }\left[\mathrm{N}^{*} \mathrm{~m} /(\mathrm{rad} / \mathrm{s})\right] \\ \mathrm{BL} & =\text { backlash [arcmin] } \\ \bar{C} & =\text { mean aerodynamic chord }[\mathrm{m}] \\ C_{L} & =\text { lift coefficient } \\ C_{L_{\alpha}} & =\text { lift coefficient due to angle of attack } \\ C_{L_{\dot{\alpha}}} & =\text { change in lift coefficient due to angle-of-attack rate } \\ C_{L_{q}} & =\text { change in lift coefficient due to pitch rate } \\ C_{L_{\dot{q}}} & =\text { change in lift coefficient due to pitch acceleration } \\ C_{m_{\alpha}} & =\text { change in pitching moment coefficient due to angle of attack } \\ C_{m_{\dot{\alpha}}} & =\text { change in pitching moment coefficient due to angle-of-attack rate } \\ C_{m_{q}} & =\text { change in pitching moment coefficient due to pitch rate }\end{array}$

\footnotetext{
${ }^{1}$ Member of Technical Staff, Fluid Mechanics Department, 2310 E. El Segundo Blvd. El Segundo, CA 90245, AIAA Associate Member

${ }^{2}$ Professor, Department of Mechanical and Aerospace Engineering, suite 1300, 3750 Elkhorn Ave., Norfolk, VA 23529, AIAA Associate Fellow.

3 Associate Professor, Department of Engineering Technology, 214 Kaufman Hall, Old Dominion University, Norfolk, VA 23529

${ }^{4}$ Senior Research Engineer, Dynamic Systems \& Control Branch, Mail Stop 308. AIAA Associate Fellow
} 


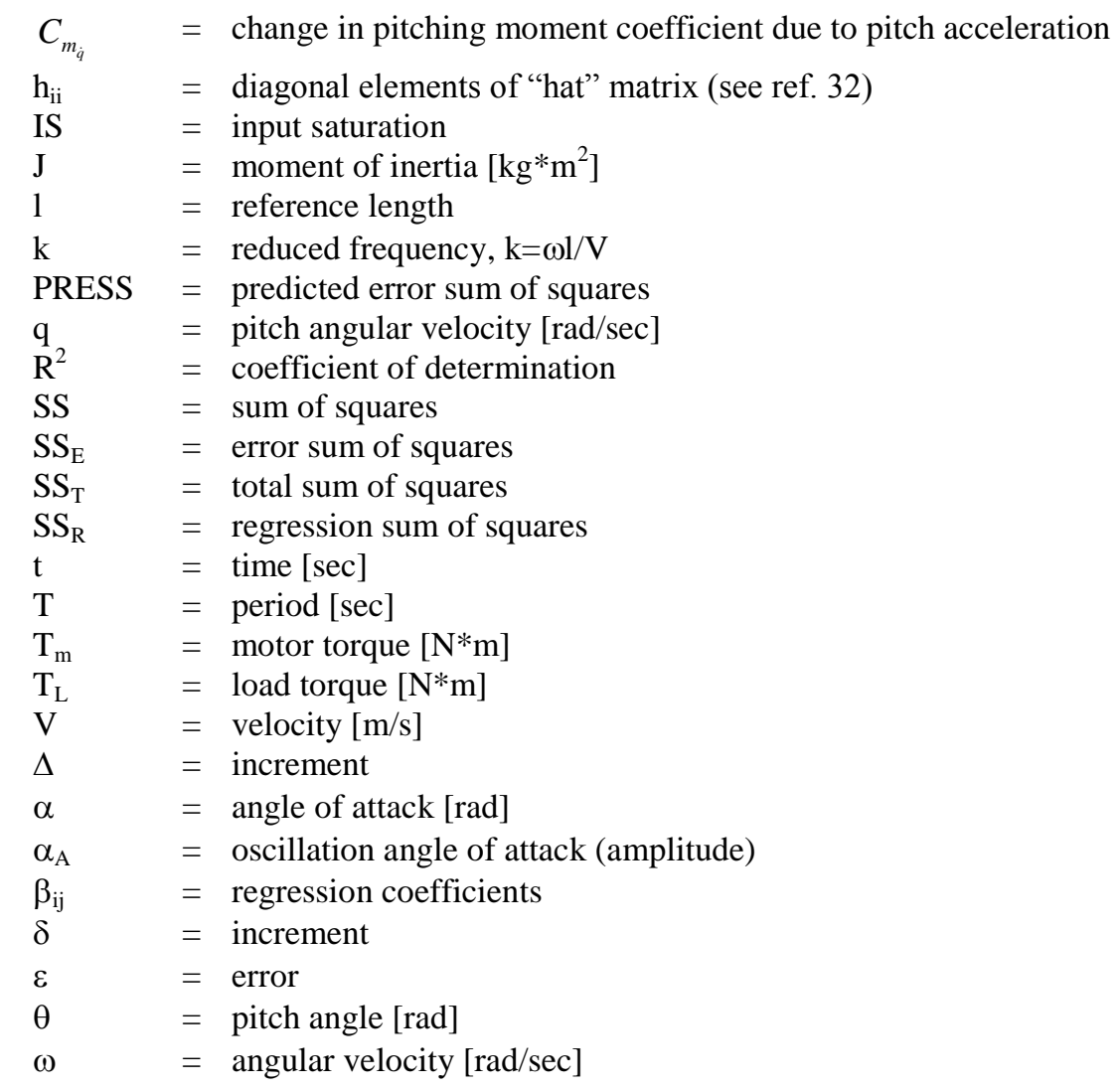

Superscripts

$=$ oscillatory data (in-phase or out-of-phase)

Subscripts

$\operatorname{adj} \quad=$ adjusted

$\mathrm{EQ} \quad=$ equivalent

\section{Introduction and Problem Definition}

$\mathrm{W}$ ITH the increasing need for high maneuverability capabilities in modern combat aircraft and for improved safety of transport aircraft under loss of control conditions there are significant shortcomings in using the conventional stability derivative modeling approach. Current prediction methods work adequately over low to moderate angles of attack. However, at high angles of attack (pre- and post-stall conditions) nonlinear unsteady aerodynamics are more pronounced. In this region the aerodynamic characteristics are based on shock waves, separated flows, vortical flows, movement of separation points, and variation of vortex breakdown locations over the surface. ${ }^{1}$

Currently, there are two primary approaches taken to formulate the nonlinear unsteady aerodynamic models - (1) analytical techniques and (2) experimental techniques. Current analytical approaches to modeling the unsteady aerodynamic characteristics of an aircraft vary greatly, and there appears to be no standard methodology. The various analytical techniques used have been reviewed by Kyle et al. and Greenwell. ${ }^{1,2}$ Dynamic test techniques range from captive, wind tunnel single degree-of-freedom and free-flying, and outside free-flying. Additional wind tunnel dynamic test techniques have been reviewed by Owens et al. and Tomek et al. ${ }^{3,4}$ The present study focuses on the most commonly used method, forced oscillation testing in a wind tunnel. Forced oscillation experiments are typically conducted at small amplitudes $(<5 \mathrm{deg})$ and single frequencies ranging from 0.1 to $10 \mathrm{~Hz}$. An example of a forced oscillation system (FOS) in the NASA Langley 12 -ft Low Speed Wind Tunnel is shown in Figure 1. 


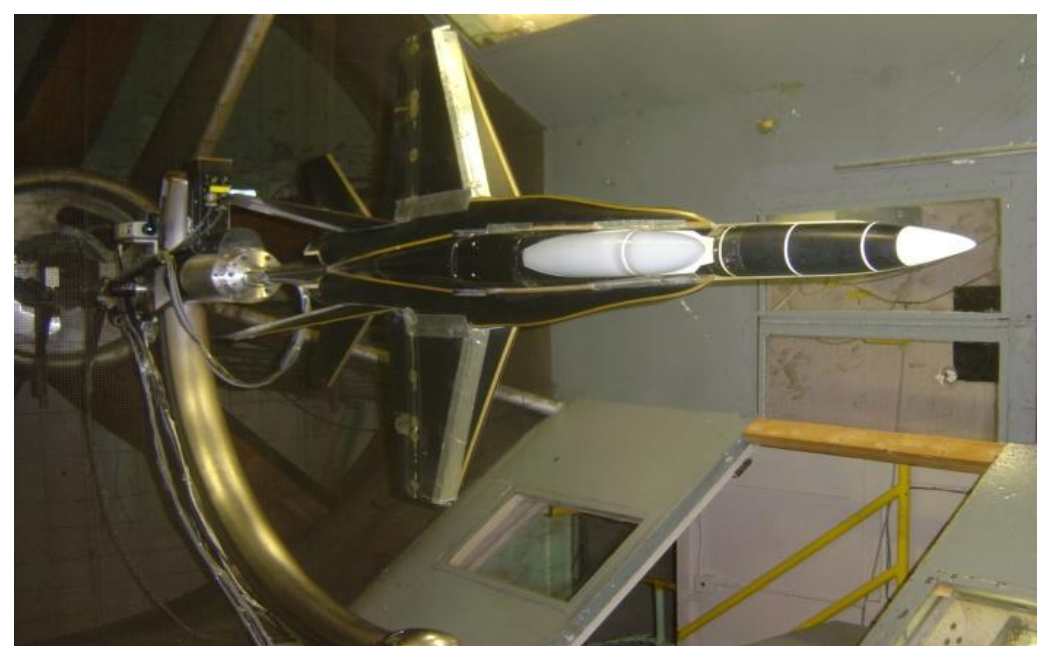

Figure 1. FOS installed in the 12-ft Wind Tunnel (roll configuration)

There are several limitations in forced oscillation testing. The apparatus used for forced oscillation is often large in size compared to the model and in close proximity to the model, causing support inference concerns. Other concerns lie in the accuracy of the force and moment measurements caused by bias and random errors from instrumentation, calibrations and tare interpolations, structural dynamics, vortex shedding, and wind tunnel fan beat frequencies. ${ }^{1,-14}$ The studies of Kim and Heim clearly demonstrated the need for proper calibration techniques and the need for adequate data sampling; both studies assumed that systematic errors could be removed by calibration alone. $^{15,} 16$ Neither study looked at the dynamic effects of the test apparatus interfering with the aerodynamic measurements.

Understanding the dynamics of a test rig is important because of the possible influence of the nonlinear behavior of components of the test rig on an aerodynamic measurement. The interactions between the mechanical components, transmission components, and electrical components introduce systematic errors that can affect the aerodynamic measurement. If the level of nonlinearities in a system can be neglected without exceeding the error tolerance then the system can be assumed linear. However, this assumption is not valid if the system nonlinearities are seen to interact with the aerodynamic loads, which pose a problem for accurately obtaining the dynamic stability derivatives that are used to develop aircraft control laws and flight dynamics studies. There is significant concern as to the overall accuracy of the measurement, particularly with forced oscillation experiments conducted at very low frequency ranges. This study attempts to examine the level of the systematic error in dynamic stability derivatives caused by mechanical and transmission components in forced oscillation test apparatuses using a high fidelity computer simulation of a dynamic pitch test rig, and assessed using the fundamental principles from Design of Experiments (DOE), and Monte Carlo methods. The study is limited to longitudinal motion only and assumes that mechanical vibrations are minimal and that aeroelastic effects may be negated.

\section{Theory}

\section{A. Determination of Stability Derivatives from Experimental Data}

Dynamic longitudinal stability derivatives cannot be measured directly because the angle-of-attack rate and pitch rate are physically identical during a forced oscillation test and it is not possible to separate the components associated with pitch rate and $\dot{\alpha}$. Therefore, the stability derivatives will take the form of a combination; for example $C_{m_{\dot{\alpha}}}+C_{m_{q}}$. The aerodynamic coefficients are assumed to be linear functions of the angle of attack, pitching velocity, and their associated rates. The incremental lift coefficient with respect to its mean value is formulated as:

$$
\Delta C_{L}=C_{L_{\alpha}} \Delta \alpha+\frac{l}{V} C_{L_{\dot{\alpha}}} \dot{\alpha}+\frac{l}{V} C_{L_{q}} q+\left(\frac{l}{V}\right)^{2} C_{L_{\dot{q}}} \dot{q}
$$

For harmonic motion, 


$$
\begin{aligned}
& \Delta \alpha=\alpha_{A} \sin \omega t \\
& \dot{\alpha}=q=\omega \alpha_{A} \cos \omega t \\
& \ddot{\alpha}=\dot{q}=-\omega^{2} \alpha_{A} \sin \omega t
\end{aligned}
$$

Then,

$$
\begin{aligned}
\Delta C_{L} & =\alpha_{A}\left(C_{L_{\alpha}}-k^{2} C_{L_{\dot{q}}}\right) \sin \omega t+\alpha_{A} k\left(C_{L_{\dot{\alpha}}}+C_{L_{q}}\right) \cos \omega t \\
& =\alpha_{A}\left(\bar{C}_{L_{\alpha}} \sin \omega t+k \bar{C}_{L_{q}} \cos \omega t\right)
\end{aligned}
$$

where the in-phase and out-of-phase components of lift coefficient have been identified as $\bar{C}_{L_{\alpha}}$ and $\bar{C}_{L_{q}}$, respectively. Using the same approach for pitching moment, the in-phase and out-of-phase pitching moment coefficients are, respectively,

$$
\begin{aligned}
& \bar{C}_{m_{\alpha}}=C_{m_{\alpha}}-k^{2} C_{m_{\dot{q}}} \\
& \bar{C}_{m_{q}}=C_{m_{q}}+C_{m_{\dot{\alpha}}}
\end{aligned}
$$

The in-phase and out-of-phase components of lift coefficient are found by integrating the time histories of $\Delta \mathrm{C}_{\mathrm{L}}$ over a given number of cycles as:

$$
\begin{aligned}
& \bar{C}_{L_{\alpha}}=\frac{2}{\alpha_{A} n_{c} T} \int_{0}^{n_{c} T} \Delta C_{L}(t) \sin \omega t d t \\
& \bar{C}_{L_{q}}=\frac{2}{\alpha_{A} n_{c} k T} \int_{0}^{n_{c} T} \Delta C_{L}(t) \cos \omega t d t
\end{aligned}
$$

where $\mathrm{T}=2 \pi / \omega$ is the period. The same approach is used to compute the in-phase and out-of-phase components for pitching moment, so that:

$$
\begin{aligned}
& \bar{C}_{m_{\alpha}}=\frac{2}{\alpha_{A} n_{c} T} \int_{0}^{n_{c} T} \Delta C_{m}(t) \sin \omega t d t \\
& \bar{C}_{m_{q}}=\frac{2}{\alpha_{A} n_{c} k T} \int_{0}^{n_{c} T} \Delta C_{m}(t) \cos \omega t d t
\end{aligned}
$$

Equations (5) and (6) have assumed that the sine waveform is of high fidelity.

\section{B. NASA Langley 12-ft Wind Tunnel Dynamic Test Rig}

A new forced oscillation system (FOS) was developed at the NASA Langley 12-ft Low Speed Wind Tunnel to improve operational efficiencies. The wind tunnel can operate at dynamic pressures up to $7 \mathrm{psf}\left(\mathrm{U}_{\infty}=77 \mathrm{ft} / \mathrm{sec}\right.$ at sea-level conditions) which corresponds to a unit Reynolds number of approximately 492,000 per foot. The test section has a turbulence level of about 0.6 percent. ${ }^{17}$ The test section airflow is produced by a 15.8 -ft diameter, 6 blade drive fan powered by a $280 \mathrm{HP}, 600 \mathrm{~V}, 600 \mathrm{rpm}$ DC motor and controlled by a $500 \mathrm{Hp} \mathrm{AC} \mathrm{motor} .^{17}$

The system supports both static and dynamic testing, and is capable of independent setting of $\alpha$ and $\beta$ combinations. For pitch oscillation testing, the system has an angle-of-attack range from $-5^{\circ}$ to $85^{\circ}$. The maximum pitch capability of the test rig is $260 \% \mathrm{sec}$ pitch rate and $2290 \% \mathrm{sec}^{2}$ pitch acceleration. For roll oscillation testing, the system has a range of displacements from \pm 170 degrees with a maximum capability of $190 \%$ sec roll rate and $12,750 \% \mathrm{sec}^{2}$ roll acceleration. The pitch and roll capabilities of the test rig are the no-load limits. Figure 2 
illustrates the overall FOS mechanical subsystem. The user prescribes the position motion, and the control algorithm executes a positional, closed-loop algorithm for tracking. The velocity control loop is managed internally using a power (BDS4) amplifier. The amplifier powers the motor which imparts the desired test article motion via the drive system components.

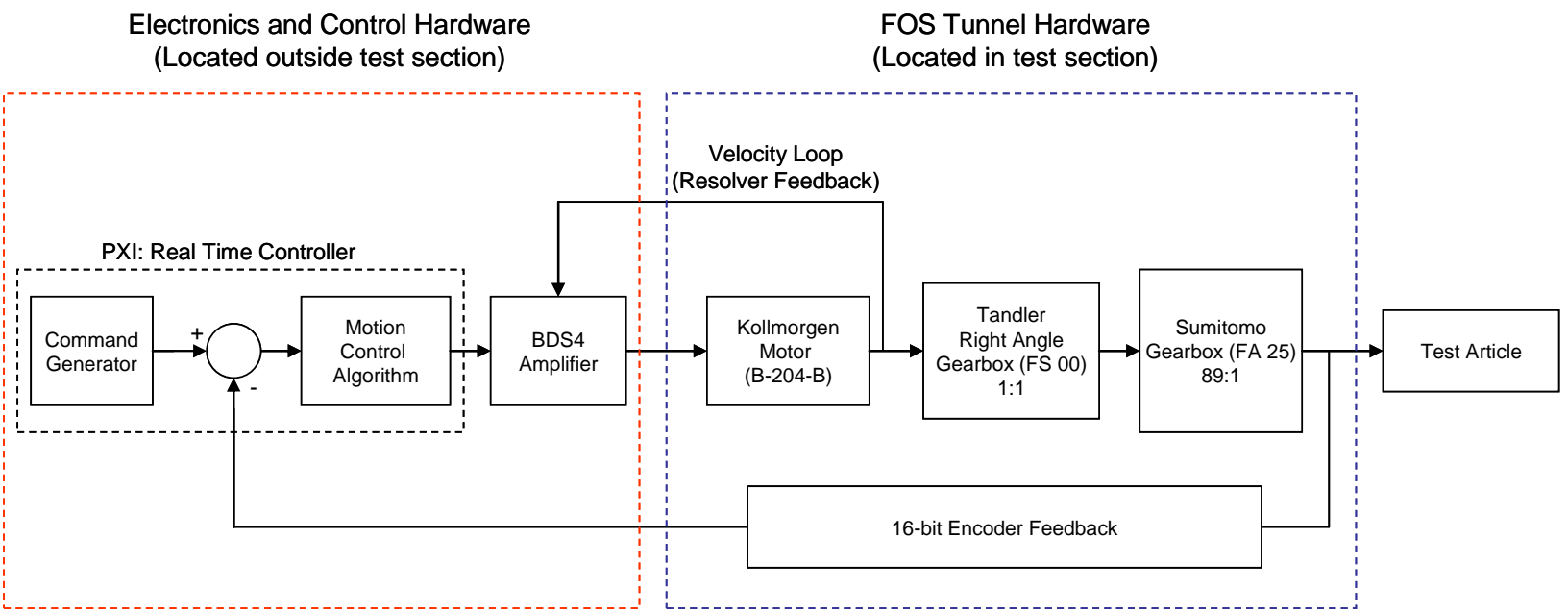

Figure 2. Overall FOS block diagram.

\section{Drive Motor and Compliantly-Coupled Drivetrain Model}

The Kollmorgen motor is a three-phase AC induction motor. A detailed derivation and explanation of the equations of motion for the motor can be found in reference 30. The desire for high performance motor drives is necessary in applications that require rapid command response and dynamic stiffness. The downside of high performance is mechanical resonance which is caused by compliance between two or more components in the mechanical transmission chain. For the case being studied, the resonance is typically the compliance between the motor and load.

Resonance can occur in a forced oscillation test when operating near resonant frequencies of the drivetrain. For the system considered in this study instability was unlikely with test frequencies between 0.1 and $10 \mathrm{~Hz}$ and the spring constants very large. Further analysis proved that the compliantly-coupled drivetrain can be modeled as a rigid body and the motor torque equation becomes simply,

$$
T_{\text {motor }}=\left(\frac{N_{1}}{N_{2}}\right)^{2}\left(B_{\text {bal }}+B_{\text {sting }}\right)+\left(\frac{N_{1}}{N_{2}}\right) \cdot T_{\text {load }}
$$

The $\mathrm{T}_{\text {load }}$ represents the aerodynamic load from the test article and the gear reduction ratio is given as a ratio of the number of teeth $(\mathrm{N})$.

\section{Computer Simulation Methodology}

A computer simulation of the FOS was created using a simplified model. Aerodynamic loads for the model were obtained by using regression models built from an existing experimental data set. The simulation was then used to perform a sensitivity study subject to changes in sting inertia, system damping, backlash, reduced frequency and input saturation.

\section{A. Computer Simulation Details}

Figure 3 provides a conceptual block diagram of the computer simulation created in Simulink@. Starting from the left, the user commands a forced oscillation profile (typically a sine wave). The commanded motion is controlled through a proportional-integral-derivative (PID) controller and a velocity signal is output and filtered before the command signal is amplified. The velocity signal is then fed into another PID controller, filtered, and saturated. Normally, a microprocessor monitors the incoming signal and then controls the motor. This step could not be modeled in Simulink due to the unknown internal process of the microprocessor. However, in this simulation 
after the saturation of the velocity signal, a three-phase current signal is modeled and output. The incoming current signal is controlled by a PI controller. The output is then transferred to a pulse-width modulator which controls and powers the motor. The torque of the motor is output, travels through the mechanical drive train and compliantly coupled system to actuate the aerodynamic model. Current, velocity, and position are fed back to their respective PID controllers ${ }^{30}$.

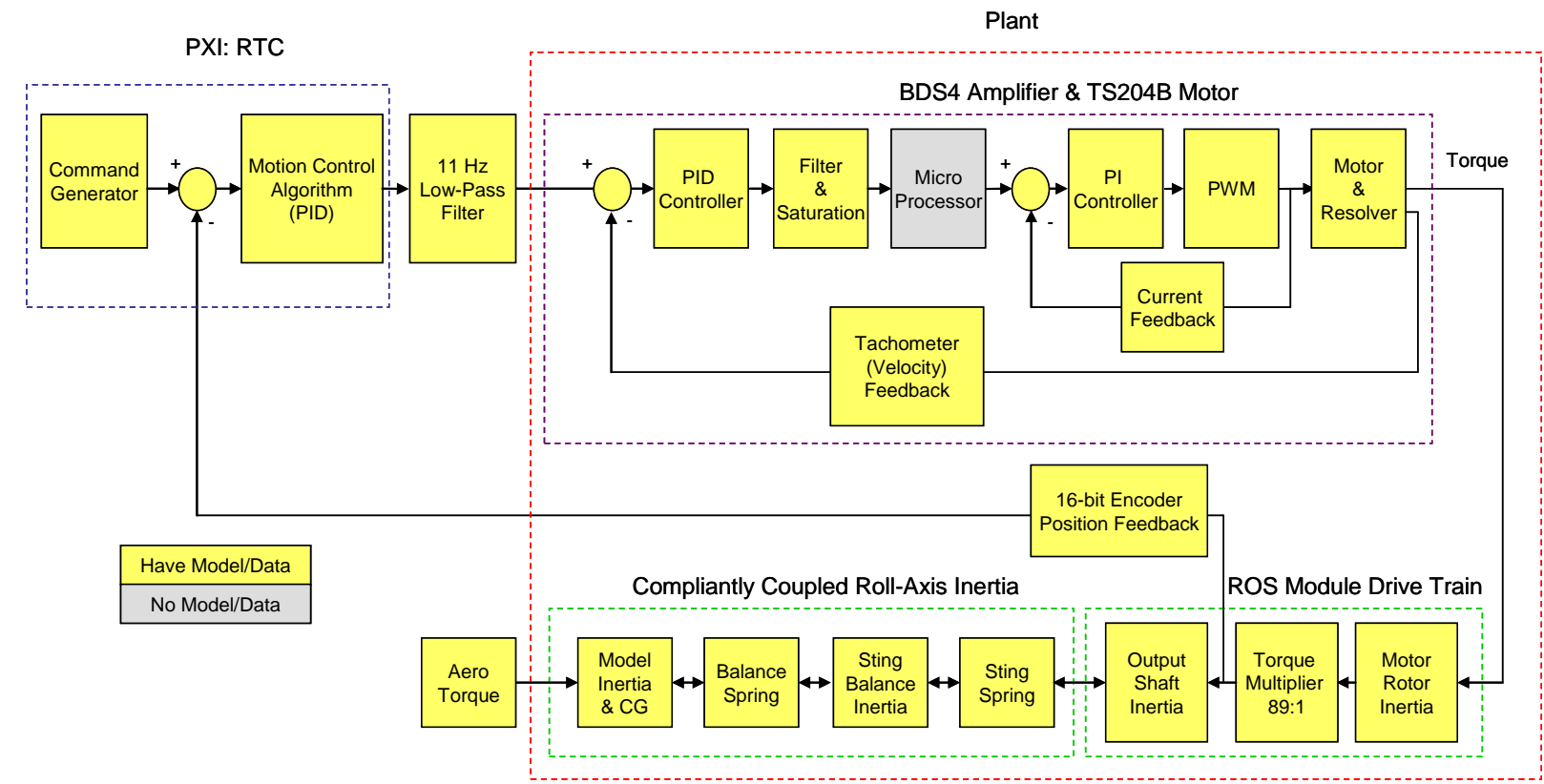

Figure 3. Detailed forced oscillation system conceptual block diagram.

To represent the aerodynamic loads, the study implemented an experimental model data set due largely to the lack of viable Computational Fluid Dynamics (CFD) codes for predicting high angle of attack and unsteady aerodynamic effects for an entire aircraft. The data set was taken from NASA LaRC 12-ft Low Speed Wind Tunnel experiments during the 1990s. ${ }^{18}$ The chosen test article was a 10\% scale model of an F16-XL aircraft. An ordinary least squares regression model was fit to the data as shown below to define the in-phase and out-of-phase lift and pitching moment coefficients in the simulation. The in-phase and out-of-phase coefficients are a function of both angle of attack and reduced frequency. Regression models were developed at a fixed angle of attack with reduced frequency as a variable. As an example, equations 8-11 show the models built for an angle of attack of $30.8^{\circ}$.

$$
\begin{aligned}
& \bar{C}_{L_{\alpha}}=82.2 k^{3}-75.4 k^{2}+23.3 k-0.387 \\
& \bar{C}_{L_{q}}=-1128 k^{3}+1005 k^{2}-298 k+31.6 \\
& \bar{C}_{m_{\alpha}}=6.82 k^{3}-8.17 k^{2}+3.19 k-0.0191 \\
& \bar{C}_{m_{q}}=-274 k^{3}+228 k^{2}-62.9 k+5.48
\end{aligned}
$$

The dynamic contribution was determined by Eq. (12) and (13) after subtracting the static contributions.

$$
\begin{aligned}
C_{L_{d y n}} & =\bar{C}_{L_{\alpha}} \theta+\left(\frac{\bar{c}}{2 V}\right) \bar{C}_{L_{q}} \dot{\theta} \\
C_{m_{d y n}} & =\bar{C}_{m_{\alpha}} \theta+\left(\frac{\bar{c}}{2 V}\right) \bar{C}_{m_{q}} \dot{\theta}
\end{aligned}
$$

Where the forcing function is based on harmonic motion, see Eq. (14). 


$$
\begin{aligned}
& \theta=\alpha_{A} \sin \omega t \\
& \dot{\theta}=\alpha_{A} \omega \cos \omega t
\end{aligned}
$$

The stability derivatives are computed using numerical integration of equations 5-6 and stored to a file.

\section{B. Computer Simulation Model Verification and Validation}

The computer simulation was validated and verified by using several steps. The first step was to insure that the theories and assumptions underlying the conceptual model are correct. The second step was to certify that the computerized model reflects the physical system based on the conceptual model. The final step was to validate individual subcomponents (i.e. motor model and aerodynamic model) of the system against either historical data or benchmark cases. An example is provided in Figure 4. Here the in-phase lift coefficient predictions are compared to the experimental data over a range of reduced frequencies and angles of attack. It should be noted that although the submodel was validated against various reduced frequencies over a range of angle of attack, only the regression models for a fixed angle of attack of $30.8^{\circ}$ and variable reduced frequency (refer to Eq. 8-11) were used in the final simulation. These regression models were chosen as representative of the general characteristics associated with the unsteady aerodynamics. For further details the reader should refer to Williams. ${ }^{30}$

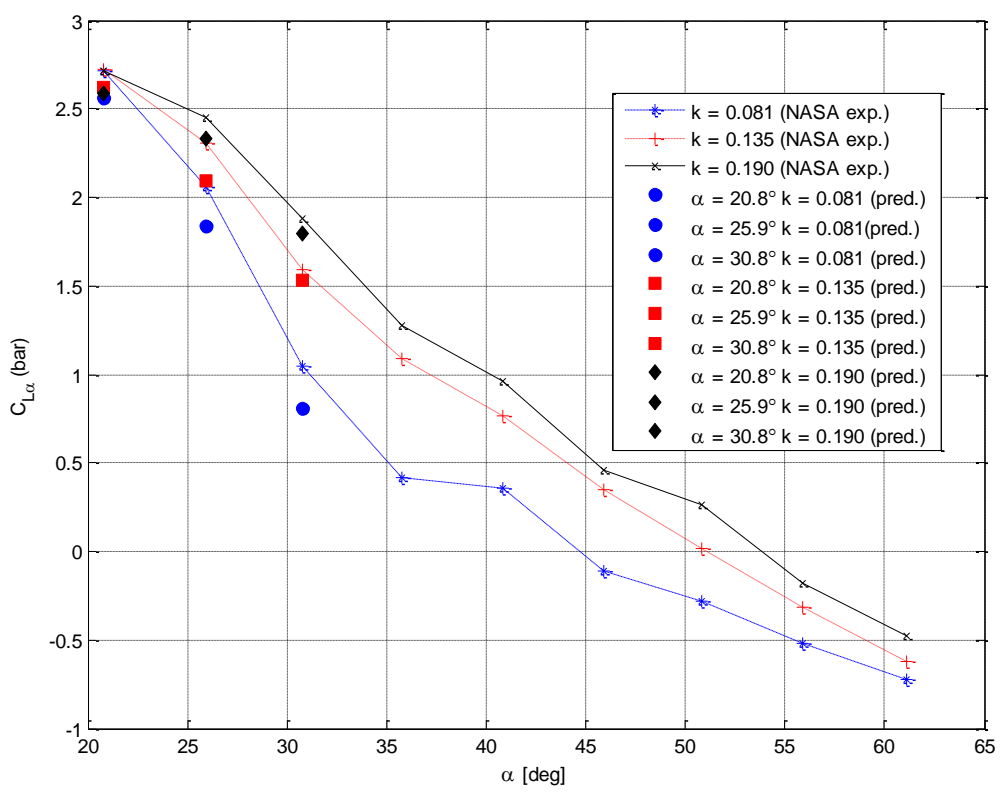

Figure 4. In-phase lift coefficient validation.

\section{Experiment Design}

The design chosen for this study is called a nested central composite face centered design and is based on the use of two, $2 \mathrm{v}^{5-1}$ fractional factorials augmented with face centered axial and center points. ${ }^{19}$ The design points of the Nested FCD in two-factor space are illustrated graphically in Figure 5. The extremes of the factor levels are set on the perimeter of the outer box. The nested factor levels are set on the perimeter of the inner box. The design supports regression modeling with pure cubic terms in addition to the full quadratic model. It should be stated that face centered designs are not rotatable. However, it is generally not a priority when the region of interest is cubeoidal. ${ }^{20}$ Adding one or two center points is sufficient to produce reasonable stability in the variance of prediction. 


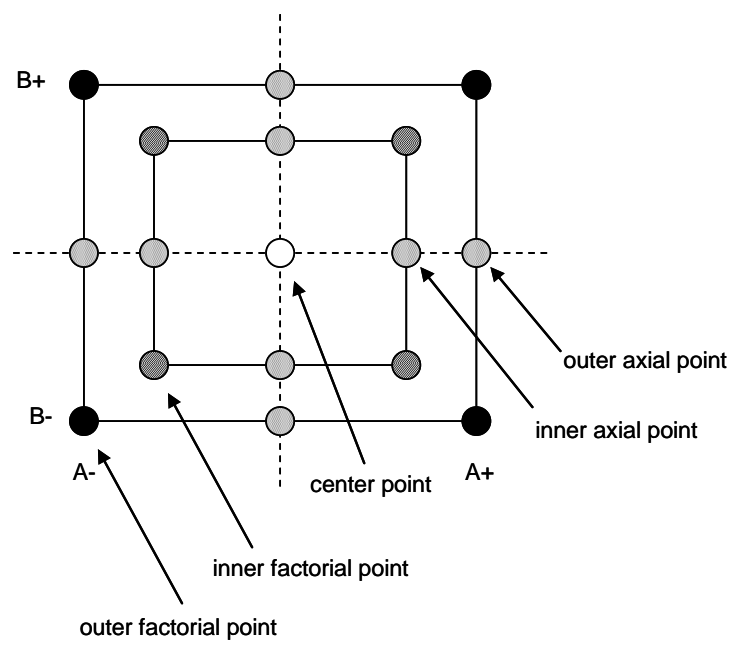

Figure 5. Nested face centered design in two factors. ${ }^{19}$

Table 1. Factor limits.

\begin{tabular}{|c|c|c|c|c|c|c|}
\hline Factor & Units & Outer Low & Inner Low & Center & Inner High & Outer High \\
\hline A & $\mathrm{kg} * \mathrm{~m}^{2}$ & 0.0001729 & 0.0002944 & 0.0004159 & 0.0005374 & 0.0006589 \\
\hline B & N-m-s/rad & 0.0000000 & 0.0020140 & 0.0040280 & 0.0060420 & 0.0080560 \\
\hline $\mathrm{C}$ & -- & 0.0810000 & 0.0857500 & 0.0905000 & 0.0952500 & 0.1000000 \\
\hline $\mathrm{D}$ & $\operatorname{arcmin}$ & 2.0000000 & 4.0000000 & 6.0000000 & 8.0000000 & 10.0000000 \\
\hline E & $\mathrm{rad}$ & 0.0809000 & \multicolumn{2}{|r|}{0.0840850} & 0.0856775 & 0.0872700 \\
\hline \multicolumn{7}{|c|}{ Factor Labeling Key: } \\
\hline \multicolumn{3}{|c|}{ Label } & & \multicolumn{2}{|c|}{ Factor } & \\
\hline \multicolumn{3}{|c|}{ A } & & \multicolumn{2}{|c|}{ Jeq (equivalent inertia) } & \\
\hline \multicolumn{3}{|c|}{ B } & & \multicolumn{2}{|c|}{ Beq (equivalent damping) } & \\
\hline \multicolumn{3}{|c|}{$\mathrm{C}$} & & \multicolumn{2}{|c|}{ k (reduced frequency) } & \\
\hline \multicolumn{3}{|c|}{$\mathrm{D}$} & & \multicolumn{2}{|c|}{ BL (backlash) } & \\
\hline \multicolumn{3}{|c|}{$\mathrm{E}$} & & \multicolumn{2}{|c|}{ IS (input saturation) } & \\
\hline
\end{tabular}

The five factors investigated in this study were: equivalent inertia, equivalent damping, reduced frequency, backlash, and input saturation. The responses were: in-phase lift coefficient, out-of-phase lift coefficient, in-phase pitching moment coefficient, and out-of-phase pitching moment coefficient. The factor limits for the design are specified in Table 1. Equivalent inertia is based on the compliance of the system, assuming a straight sting (Outer Low) or a bent sting (Outer High). Equivalent damping is similar; however, it assumes no damping (Outer Low) and the system compliance damping (Outer High). The reduced frequency range is based on experimental data. The backlash range in the gear drive is based on published data from the manufacturer. ${ }^{21}$ Finally, the input saturation range is based on observations from experimental data noted by Kim et al. ${ }^{22}$ Experimental results have shown evidence of clipping in the data. For example, a sinusoidal wave form is input into the system and the output should be a sinusoidal waveform; however, experimental results showed the peaks of the waveform being clipped. This clipping was traced back to input saturation. The inner face center design points were determined by $1 / 2$ of the distance to the outer face center design points.

The nested face centered design test matrix was analyzed using Design Expert@, commercial software; see Table 2. The simulation was run for each test case listed in Table 2. Care must be taken when analyzing results of a response surface methodology with a deterministic computer simulation. 
Table 2. $2^{5-1}$ nested face centered design test matrix (center run is shown as bold).

\begin{tabular}{|c|c|c|c|c|c|c|c|c|c|c|c|}
\hline Run & Jeq (A) & Beq (B) & $\mathrm{k}(\mathrm{C})$ & BL (D) & IS (E) & Run & Jeq & Beq & $\mathrm{k}$ & $\mathrm{BL}$ & IS \\
\hline 1 & 0.0006589 & 0 & 0.081 & 10 & 0.08727 & 30 & 0.0002944 & 0.006042 & 0.08575 & 4 & 0.0824925 \\
\hline 2 & 0.0004159 & 0.004028 & 0.0905 & 6 & 0.084085 & 31 & 0.0005374 & 0.006042 & 0.08575 & 4 & 0.0856775 \\
\hline 3 & 0.0004159 & 0.004028 & 0.0905 & 10 & 0.084085 & 32 & 0.0002944 & 0.002014 & 0.09525 & 4 & 0.0824925 \\
\hline 4 & 0.0006589 & 0.008056 & 0.1 & 2 & 0.0809 & 33 & 0.0005374 & 0.002014 & 0.09525 & 4 & 0.0856775 \\
\hline 5 & 0.0004159 & 0.004028 & 0.1 & 6 & 0.084085 & 34 & 0.0002944 & 0.006042 & 0.09525 & 4 & 0.0856775 \\
\hline 6 & 0.0004159 & 0.004028 & 0.0905 & 2 & 0.084085 & 35 & 0.0005374 & 0.006042 & 0.09525 & 4 & 0.0824925 \\
\hline 7 & 0.0006589 & 0.008056 & 0.081 & 10 & 0.0809 & 36 & 0.0002944 & 0.002014 & 0.08575 & 8 & 0.0824925 \\
\hline 8 & 0.0001729 & 0 & 0.1 & 10 & 0.08727 & 37 & 0.0005374 & 0.002014 & 0.08575 & 8 & 0.0856775 \\
\hline 9 & 0.0006589 & 0 & 0.081 & 2 & 0.0809 & 38 & 0.0002944 & 0.006042 & 0.08575 & 8 & 0.0856775 \\
\hline 10 & 0.0006589 & 0.004028 & 0.0905 & 6 & 0.084085 & 39 & 0.0005374 & 0.006042 & 0.08575 & 8 & 0.0824925 \\
\hline 11 & 0.0001729 & 0.008056 & 0.1 & 10 & 0.0809 & 40 & 0.0002944 & 0.002014 & 0.09525 & 8 & 0.0856775 \\
\hline 12 & 0.0004159 & 0 & 0.0905 & 6 & 0.084085 & 41 & 0.0005374 & 0.002014 & 0.09525 & 8 & 0.0824925 \\
\hline 13 & 0.0004159 & 0.004028 & 0.081 & 6 & 0.084085 & 42 & 0.0002944 & 0.006042 & 0.09525 & 8 & 0.0824925 \\
\hline 14 & 0.0006589 & 0.008056 & 0.1 & 10 & 0.08727 & 43 & 0.0005374 & 0.006042 & 0.09525 & 8 & 0.0856775 \\
\hline 15 & 0.0006589 & 0 & 0.1 & 10 & 0.0809 & 44 & 0.0002944 & 0.004028 & 0.0905 & 6 & 0.084085 \\
\hline 16 & 0.0001729 & 0 & 0.081 & 2 & 0.08727 & 45 & 0.0005374 & 0.004028 & 0.0905 & 6 & 0.084085 \\
\hline 17 & 0.0001729 & 0.008056 & 0.081 & 10 & 0.08727 & 46 & 0.0004159 & 0.002014 & 0.0905 & 6 & 0.084085 \\
\hline 18 & 0.0001729 & 0.004028 & 0.0905 & 6 & 0.084085 & 47 & 0.0004159 & 0.006042 & 0.0905 & 6 & 0.084085 \\
\hline 19 & 0.0001729 & 0 & 0.081 & 10 & 0.0809 & 48 & 0.0004159 & 0.004028 & 0.08575 & 6 & 0.084085 \\
\hline 20 & 0.0001729 & 0 & 0.1 & 2 & 0.0809 & 49 & 0.0004159 & 0.004028 & 0.09525 & 6 & 0.084085 \\
\hline 21 & 0.0004159 & 0.004028 & 0.0905 & 6 & 0.08727 & 50 & 0.0004159 & 0.004028 & 0.0905 & 4 & 0.084085 \\
\hline 22 & 0.0006589 & 0 & 0.1 & 2 & 0.08727 & 51 & 0.0004159 & 0.004028 & 0.0905 & 8 & 0.084085 \\
\hline 23 & 0.0001729 & 0.008056 & 0.081 & 2 & 0.0809 & 52 & 0.0004159 & 0.004028 & 0.0905 & 6 & 0.0824925 \\
\hline 24 & 0.0004159 & 0.004028 & 0.0905 & 6 & 0.0809 & 53 & 0.0004159 & 0.004028 & 0.0905 & 6 & 0.0856775 \\
\hline 25 & 0.0006589 & 0.008056 & 0.081 & 2 & 0.08727 & & & & & & \\
\hline 26 & 0.0001729 & 0.008056 & 0.1 & 2 & 0.08727 & & & & & & \\
\hline 27 & 0.0004159 & 0.008056 & 0.0905 & 6 & 0.084085 & & & & & & \\
\hline 28 & 0.0002944 & 0.002014 & 0.08575 & 4 & 0.0856775 & & & & & & \\
\hline 29 & 0.0005374 & 0.002014 & 0.08575 & 4 & 0.0824925 & & & & & & \\
\hline
\end{tabular}

\section{A. Statistics and Deterministic Computer Models}

Response surface methodology (RSM) has been used successfully with computer simulation models of physical systems. A few examples are Barton $(1992,1994)$ and Simpson et al. (1997). ${ }^{23-25}$ The goal of RSM is to build a regression model of the system being modeled by the computer simulation - a regression metamodel. Although RSM is primarily intended for applications with random error, deterministic applications are appropriate and the analysis is simplified. Care must be taken when using statistics to develop the regression metamodel. The nature of the computer simulation is represented as an input-output relation,

$$
y=f(x)
$$

Then an estimated output is represented as

$$
\hat{y}=g(x)+\varepsilon_{\text {bias }}
$$

where $\mathrm{g}(\mathrm{x})$ is the metamodel, and $\varepsilon_{\text {bias }}$ is the error of approximation. The relationship conflicts with the use of Analysis of Variance (ANOVA) with least squares regression. ${ }^{26}$ Consequently, the response surface fitting is hampered by the following constraints. ${ }^{27,28}$

1. The response surface model adequacy is determined solely by systematic bias.

2. The usual measures of uncertainty derived from least squares residuals have no obvious statistical meaning; deterministic measures of uncertainty exist. 
3. The notions of experimental blocking, replication, and randomization are irrelevant.

Statistical measures such as pure error, F-statistics, and mean squared error for verification of model adequacy have no statistical meaning because they are all based on random error. Care should be taken when using commercial software because manufacturers employ these types of statistical measures for developing a model. These measures have no statistical meaning since they assume that observations include an error term, which has a mean of zero and a non-zero standard deviation. The relative size of the coded (centered and scaled) regression model terms and sum of squares (SS) contributions may be compared.

\section{B. Fitting and Validating of Regression Metamodels}

The best metrics to verify and validate the metamodels (i.e. regression models of the in-phase and out-of-phase coefficients determined by the computer simulation) are the coefficients of determination, cross-validation and point prediction methods ${ }^{26,27}$ The classic coefficient of determination measure is

$$
R^{2}=\frac{S S_{R}}{S S_{T}}=1-\frac{S S_{E}}{S S_{T}} \quad \text { where } \quad 0 \leq R^{2} \leq 1
$$

Values of $R^{2}$ that are close to one imply that the variability in the response is explained by the regression model. ${ }^{29}$ Caution should be exercised when using $R^{2}$. Increasing the number of regression model terms always increases $R^{2}$ regardless of the value of the contribution of the term. This does not necessarily mean that the model is an accurate predictor and the model may become over-fitted. Consequently, $R_{a d j}^{2}$ is used as an indicator of model adequacy.

$$
R_{a d j}^{2}=1-\frac{S S_{E} /(n-p)}{S S_{T} /(n-1)}
$$

The adjusted $R^{2}$ penalizes the model for adding terms that are not meaningful, so it is most useful in evaluating and comparing candidate regression models, particularly when working with deterministic simulations. Cross validation is useful when collecting new data for validation purposes, but it is not possible. A reasonable procedure is to split the available data into two parts called the estimation data and the prediction data. ${ }^{29}$ The estimation data are used to build the regression model, and the prediction data are then used to study the predictive ability of the model. ${ }^{26}$ One useful statistic for cross validation is the prediction error sum of squares (PRESS). The PRESS residuals are defined as $e_{(i)}=y_{i}-\hat{y}_{(i)}$ where $\hat{y}_{(i)}$ is the predicted value of the $i^{\text {th }}$ observed response based on a model fit to the remaining $n$ - 1 sample points. ${ }^{26}$ Thus, the PRESS statistic is defined as a measure of model quality; see Eq. (20).

$$
\operatorname{PRESS}=\sum_{i=1}^{n}\left[y_{i}-\hat{y}_{(i)}\right]^{2}=\sum_{i=1}^{n}\left(\frac{e_{i}}{1-h_{i i}}\right)^{2}
$$

Generally, when using the PRESS statistic, small values of PRESS are desired. Using the PRESS statistic, the predicted $R^{2}$ is described as

$$
R_{\text {pred }}^{2}=1-\frac{P R E S S}{S S_{T}}
$$

This statistic gives an indication of the predictive capability of the regression model and a sense of how much variability in new observations the model might be expected to explain. ${ }^{26}$ Table 3 summarizes the fit statistics.

The final validation procedure is to apply a few confirmation runs using point prediction to test the regression metamodels. ${ }^{26} \mathrm{~A}$ few points within the design space were selected that were not used to build the regression model. The results of the regression metamodel were compared with the simulation results. The percent difference was calculated to provide a measure of prediction for the regression metamodel, compared to the simulation. The percent difference between the metamodel and simulation ranged from $0.1 \%$ to $7 \%$. 
Table 3. Regression metamodel fit summary statistics.

\begin{tabular}{|c|c|c|c|}
\hline \multicolumn{4}{|c|}{ In-Phase Lift Coefficient } \\
\hline \multirow{3}{*}{$\begin{array}{l}\text { Std. Dev. } \\
\text { Mean }\end{array}$} & 0.0235 & R-Squared & 0.8957 \\
\hline & \multirow[t]{2}{*}{1.1047} & Adj R-Squared & 0.8305 \\
\hline & & Pred R-Squared & 0.7670 \\
\hline \multicolumn{4}{|c|}{ Out-of-phase Lift Coefficient } \\
\hline \multirow{3}{*}{$\begin{array}{l}\text { Std. Dev. } \\
\text { Mean }\end{array}$} & 0.2294 & R-Squared & 0.9574 \\
\hline & 12.6622 & Adj R-Squared & 0.9307 \\
\hline & & Pred R-Squared & 0.9110 \\
\hline \multicolumn{4}{|c|}{ In-phase Pitching Moment Coefficient } \\
\hline \multirow{3}{*}{$\begin{array}{l}\text { Std. Dev. } \\
\text { Mean }\end{array}$} & 0.00273 & R-Squared & 0.9452 \\
\hline & 0.20025 & Adj R-Squared & 0.9109 \\
\hline & & Pred R-Squared & 0.8762 \\
\hline \multicolumn{4}{|c|}{ Out-of-phase Pitching Moment Coefficient } \\
\hline \multirow{3}{*}{$\begin{array}{c}\text { Std. Dev. } \\
\text { Mean }\end{array}$} & 0.0436 & R-Squared & 0.9575 \\
\hline & 1.5613 & Adj R-Squared & 0.9310 \\
\hline & & Pred R-Squared & 0.9089 \\
\hline
\end{tabular}

\section{Monte Carlo Simulations}

The study used two different Monte Carlo simulation approaches for the uncertainty analysis. The Appendix contains flowcharts that detail the two approaches. The two approaches are (1) a Taylor series based sensitivity and (2) a regression model based sensitivity. ${ }^{3}$

\section{A. Taylor Series Based Sensitivity Analysis}

The first approach uses the classical Taylor series based sensitivity analysis in conjunction with a Monte Carlo simulation to determine the uncertainty. For a Taylor series based sensitivity approach, the partial derivatives of Eq. 21 were computed from the regression (coded variables) models. The sensitivities are computed at a given nominal setting of the factors and correlations between factors are not considered, Eq. 22.

$$
\left[\left.\begin{array}{cccc}
\frac{\partial \bar{C}_{L_{\alpha}}}{\partial J_{E Q}} & \frac{\partial \bar{C}_{L_{\alpha}}}{\partial B_{E Q}} & \cdots & \frac{\partial \bar{C}_{L_{\alpha}}}{\partial I S} \\
\frac{\partial \bar{C}_{L_{q}}}{\partial J_{E Q}} & \ddots & & \vdots \\
\vdots & & \ddots & \vdots \\
\frac{\partial \bar{C}_{m_{q}}}{\partial J_{E Q}} & \cdots & \cdots & \frac{\partial \bar{C}_{m_{q}}}{\partial I S}
\end{array}\right|_{J_{E Q_{0}, B_{E Q_{0}} k_{0}, B L_{0}, I S_{0}}}\right.
$$

The algorithm sampled a pseudo-population with 100,000 trials. Uniform distributions were chosen for $\delta \mathrm{J}_{\mathrm{EQ}}$ and $\delta \mathrm{B}_{\mathrm{EQ}}$ and normal distributions were chosen for $\delta \mathrm{BL}$ and $\delta \mathrm{IS}$. No distribution was used for $\delta \mathrm{k}$. Finally, the procedure computes the in-phase and out-of-phase lift and pitching moment coefficients and concludes with summary statistics and confidence intervals. 


$$
\begin{aligned}
\delta \bar{C}_{L_{\alpha}} & =\left[\left(\frac{\partial \bar{C}_{L_{\alpha}}}{\partial J_{E Q}} \delta J_{E Q}\right)^{2}+\left(\frac{\partial \bar{C}_{L_{\alpha}}}{\partial B_{E Q}} \delta B_{E Q}\right)^{2}+\cdots+\left(\frac{\partial \bar{C}_{L_{\alpha}}}{\partial I S} \delta I S\right)^{2}\right]^{1 / 2} \\
\delta \bar{C}_{L_{q}} & =\cdots \\
\delta \bar{C}_{m_{\alpha}} & =\cdots \\
\delta \bar{C}_{m_{q}} & =\cdots \\
\bar{C}_{L_{\alpha}} & =\left.\bar{C}_{L_{\alpha}}\right|_{0}+\delta \bar{C}_{L_{\alpha}} \\
\bar{C}_{L_{q}} & =\cdots \\
\bar{C}_{m_{\alpha}} & =\cdots \\
\bar{C}_{m_{q}} & =\cdots
\end{aligned}
$$

\section{B. Direct Regression Model Approach}

The second approach is a direct regression model-based Monte Carlo method. A pseudo-population of the factors (i.e. $\mathrm{J}_{\text {eq }}, \mathrm{B}_{\mathrm{eq}}, \mathrm{BL}$, and IS) was directly substituted into the regression models. A run of 100,000 Monte Carlo trials was performed. The samples for each factor are direct inputs for the metamodel regression models. A flowchart of the procedure is provided in the Appendix. Again, no distribution was used for the reduced frequency factor.

\section{Test Cases}

Several test cases were run and are summarized in Table 4 using both Monte Carlo simulation approaches described previously. The first test case represents the ideal factor settings for a test rig operating at a low reduced frequency. The ideal settings were based on reported information from NASA LaRC. The equivalent inertia and damping are set at their maximum limit. Backlash is set at its minimum and input saturation is not present. The reader should refer back to Table 1 for values of these settings. The second test case uses the factor settings at the center of the design space. The third test case uses factor settings at the low levels within the design space. It also assumes that input saturation is significant. The final two cases were chosen randomly within the design space. Confidence intervals were calculated using the method of reference 31 for skewed distributions. ${ }^{31}$

\section{Results and Discussion}

All of the test cases showed highly skewed histograms of the in-phase and out-of-phase lift and pitching moment coefficients. An example is shown in Figure 6 for the in-phase lift coefficient. This demonstrates the high degree of nonlinearity in the system. Tables (4) and (5) summarize the 95\% probability confidence intervals for all test cases for each Monte Carlo simulation approach. 


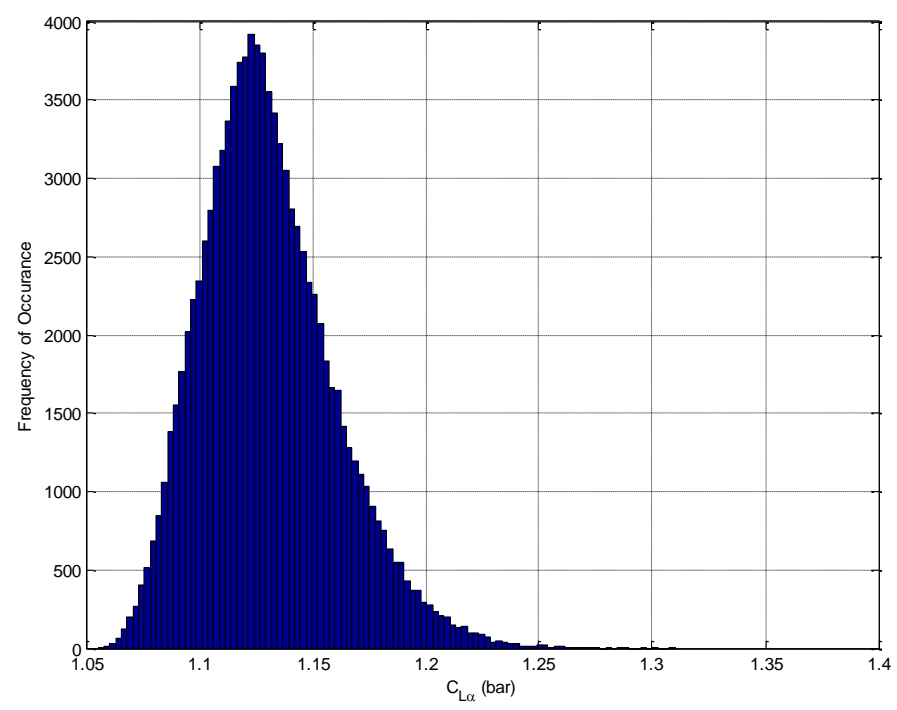

Figure 6. Histogram for in-phase lift coefficient.

Table 4. Summary of $95 \%$ confidence intervals using Taylor series based sensitivity analysis.

\begin{tabular}{|c|l|c|l|}
\hline Test Case & 95\% Confidence Interval & Test Case & 95\% Confidence Interval \\
\hline$\# 1$ & $1.0816 \leq \bar{C}_{L_{\alpha}} \leq 1.1967$ & $\# 4$ & $1.0185 \leq \bar{C}_{L_{\alpha}} \leq 1.1910$ \\
& $14.2512 \leq \bar{C}_{L_{q}} \leq 15.3689$ & & $14.2323 \leq \bar{C}_{L_{q}} \leq 15.4076$ \\
& $0.1942 \leq \bar{C}_{m_{\alpha}} \leq 0.2070$ & & $0.1853 \leq \bar{C}_{m_{\alpha}} \leq 0.2062$ \\
& $1.8614 \leq \bar{C}_{m_{q}} \leq 2.0782$ & & $1.8731 \leq \bar{C}_{m_{q}} \leq 2.1218$ \\
\hline$\# 2$ & $1.1225 \leq \bar{C}_{L_{\alpha}} \leq 1.1842$ & & \\
\hline$\# 3$ & $12.7585 \leq \bar{C}_{L_{q}} \leq 13.4310$ & & $1.1643 \leq \bar{C}_{L_{\alpha}} \leq 1.3211$ \\
& $0.2023 \leq \bar{C}_{m_{\alpha}} \leq 0.2096$ & & $11.7270 \leq \bar{C}_{L_{q}} \leq 12.7796$ \\
& $1.5772 \leq \bar{C}_{m_{q}} \leq 1.7004$ & & $0.2111 \leq \bar{C}_{m_{\alpha}} \leq 0.2303$ \\
& $1.0714 \leq \bar{C}_{L_{\alpha}} \leq 1.2526$ & & $1.3899 \leq \bar{C}_{m_{q}} \leq 1.6111$ \\
\hline & $12.7585 \leq \bar{C}_{L_{q}} \leq 15.4326$ & & \\
& $0.1919 \leq \bar{C}_{m_{\alpha}} \leq 0.2138$ & & \\
& $1.8436 \leq \bar{C}_{m_{q}} \leq 2.1181$ & & \\
\hline
\end{tabular}


Table 5. Summary of $95 \%$ confidence intervals using direct regression model method.

\begin{tabular}{|c|l|c|l|}
\hline Test Case & 95\% Confidence Interval & Test Case & 95\% Confidence Interval \\
\hline$\# 1$ & $0.7664 \leq \bar{C}_{L_{\alpha}} \leq 1.3756$ & $\# 4$ & $0.7786 \leq \bar{C}_{L_{\alpha}} \leq 1.3573$ \\
& $10.5639 \leq \bar{C}_{L_{q}} \leq 16.9628$ & & $10.4190 \leq \bar{C}_{L_{q}} \leq 15.5613$ \\
& $0.2290 \leq \bar{C}_{m_{\alpha}} \leq 0.3538$ & & $0.1568 \leq \bar{C}_{m_{\alpha}} \leq 0.2257$ \\
& $1.1743 \leq \bar{C}_{m_{q}} \leq 2.3590$ & & $1.1576 \leq \bar{C}_{m_{q}} \leq 2.1568$ \\
& $0.9644 \leq \bar{C}_{L_{\alpha}} \leq 1.1387$ & & \\
\hline$\# 2$ & $12.3625 \leq \bar{C}_{L_{q}} \leq 13.9079$ & & $0.8593 \leq \bar{C}_{L_{\alpha}} \leq 1.4391$ \\
& $0.1832 \leq \bar{C}_{m_{\alpha}} \leq 0.2042$ & & $8.5762 \leq \bar{C}_{L_{q}} \leq 14.1788$ \\
& $1.5027 \leq \bar{C}_{m_{q}} \leq 1.8014$ & & $0.1734 \leq \bar{C}_{m_{\alpha}} \leq 0.2438$ \\
& $0.8238 \leq \bar{C}_{L_{\alpha}} \leq 1.5077$ & & $0.8004 \leq \bar{C}_{m_{q}} \leq 1.8465$ \\
& $8.7298 \leq \bar{C}_{L_{q}} \leq 15.1489$ & & \\
& $0.1624 \leq \bar{C}_{m_{\alpha}} \leq 0.2452$ & & \\
& $0.8564 \leq \bar{C}_{m_{q}} \leq 2.0756$ & & \\
\hline 3 & & & \\
\hline
\end{tabular}

The sensitivity analysis via a Taylor series (TS) expansion is simple, but its use has several drawbacks. It is based on computing derivatives and numerical differentiation can be difficult for complex functions. The TS expansion assumes the response is nearly linear over a small range. It will not always be easy to determine whether the approximations involved using these methods are acceptable. The regression model (RM) Monte Carlo method does not suffer from this problem because it can reach an arbitrary level of accuracy. In addition, the TS method is strictly based on the statistical moments of each parameter and does not directly incorporate the parameter probability distribution(s). ${ }^{31}$ One of the major drawbacks is that the method lacks coupled variable effects. If an input variable is statistically correlated, one-factor-at-a-time sensitivity analysis does not address such correlations. Attempting to evaluate all the potential combinations of input parameters can be unmanageable. Also, high order estimates may be necessary to adequately address highly skewed distributions.

The regression metamodel (RM) Monte Carlo method obtains high accuracy by using a sufficiently large number of runs. The RM Monte Carlo method can suffer from improper selection of probability distributions either from inadequate data or lack of understanding of the underlying physical process.

The TS Monte Carlo method may be used to obtain preliminary answers. However, the RM Monte Carlo method is preferred when error propagation with a complex system is being studied because the method is easily implemented and generally applicable.

The TS Monte Carlo method predicts that the response variability ranges from approximately $3 \%$ to $6 \%$ of the mean responses over all test cases. On the other hand, the RM model Monte Carlo method predicts that the response variability ranges from approximately $3 \%$ to $40 \%$ of the mean responses over all test cases.

The most significant finding of the study is that researchers using different test rigs can have, even with the same aircraft model, significantly varied results due only to the differences in system dynamic parameters. Many researchers often assume that bias errors can simply be averaged out or that they are negligible. However, the parameters play a larger role in that the systematic errors interact with the aerodynamics, even with proper calibration of the forced oscillation test rig. The large variability predicted by the RM Monte Carlo method indicates that the bias effects are interacting with the aerodynamics. For example, input saturation causes the dynamic contributions of lift coefficient and pitching moment coefficient to have missing data at the peaks and troughs of the sine wave; an example is shown in Figure 7. This result has also been shown in experimental results; refer to the work of Kim et al. ${ }^{22}$ The poor prediction of the stability derivatives is problematic because the analysis 
used to compute the in-phase and out-of-phase coefficients assumes that the sine fidelity is high. The analysis used simply solves for the area under the curve to determine the in-phase and out-of-phase coefficients. Therefore, one cause of the poor prediction is due to poor sine fidelity caused by input saturation.

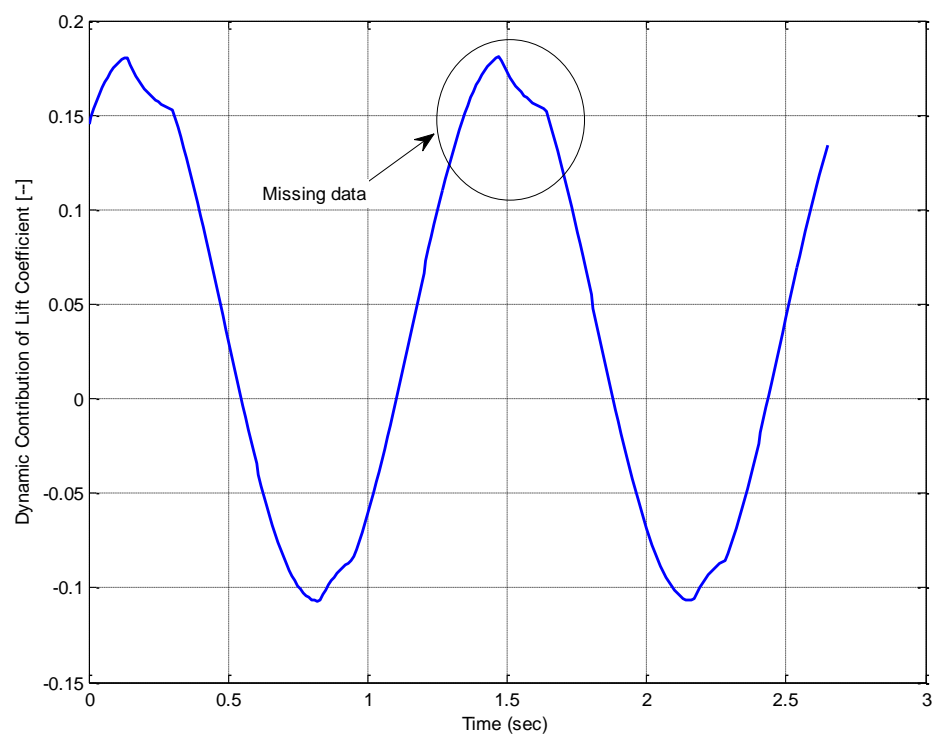

Figure 7: Incomplete sinusoidal waveform of dynamic contribution of lift coefficient

The bias effect of backlash is also highly problematic. Although some backlash is necessary in all geared systems to allow a certain amount of clearance between the components transmitting the motion under the load to avoid interference, wear, and excessive heat generation, it can be particularly challenging if the backlash is large (i.e. 8 arcmin or higher). Backlash is also not important in applications where there is no load reversal or the position after a reversal is not critical. However, forced oscillation wind tunnel testing requires precision positioning with frequent load reversal. Backlash can directly influence the positioning. When the gears are separated, the load is no longer under control, control is only retained on the motor side. When the gears again mate, backlash can introduce a nonlinear vibration effect that may be on the same order of magnitude as the aerodynamic effects being measured. Furthermore, the coupling effects between the systematic errors make it very difficult to decouple them from the aerodynamic measurement. Referring to Table 6, the coded (i.e. centered and scaled) regression metamodels can be used to examine the magnitude of the effects. Factor labels are those given in table 1 .

Reduced frequency is the most dominant contributor to the in-phase and out-of-phase components; it is shown in bold in Table 6. This result is required since the aerodynamic model developed was based on reduced frequency. Interestingly, the coupling effects are about the same order of magnitude. The coupling makes it difficult to determine which systematic error is dominating and should be eliminated. For example, looking at the in-phase pitching moment coefficient, the interaction between backlash and input saturation (i.e. D*E) has a similar magnitude effect compared to an interaction between equivalent damping and backlash (i.e. B*D). The backlash and input saturation interaction also have the same order effect as the interaction between equivalent damping and reduced frequency (i.e. $\mathrm{B}^{*} \mathrm{C}$ ). No one effect is dominating. Overall combined contributions are affecting the final result making it difficult to decouple the systematic errors from the aerodynamics. 
Table 6: Coded Regression Metamodels

\begin{tabular}{|c|c|c|c|c|c|c|c|}
\hline \multicolumn{2}{|c|}{ In-Phase Lift Coefficient } & \multicolumn{2}{|c|}{ Out-of-Phase Lift Coefficient } & \multicolumn{2}{|c|}{$\begin{array}{c}\text { In-Phase Pitching Moment } \\
\text { Coefficient }\end{array}$} & \multicolumn{2}{|c|}{$\begin{array}{l}\text { Out-of-Phase Pitching } \\
\text { Moment Coefficient }\end{array}$} \\
\hline $\bar{C}_{L_{\alpha}}$ & $=$ & $\bar{C}_{L_{q}}$ & $=$ & $\bar{C}_{m_{\alpha}}$ & $=$ & $\bar{C}_{m_{q}}$ & $=$ \\
\hline $1.108 \mathrm{E}+00$ & & $1.264 \mathrm{E}+01$ & & $2.005 E-01$ & & $1.555 \mathrm{E}+00$ & \\
\hline $2.525 \mathrm{E}-02$ & ${ }^{*} \mathrm{~A}$ & $-3.061 E-01$ & ${ }^{*} \mathrm{~A}$ & 3.524E-03 & ${ }^{*} A$ & $-5.061 \mathrm{E}-02$ & ${ }^{*} \mathrm{~A}$ \\
\hline 2.443E-02 & ${ }^{*} \mathrm{~B}$ & $-2.369 \mathrm{E}-01$ & ${ }^{*} \mathrm{~B}$ & $2.585 \mathrm{E}-03$ & ${ }^{*} \mathrm{~B}$ & $-4.668 \mathrm{E}-02$ & ${ }^{*} \mathrm{~B}$ \\
\hline $1.140 \mathrm{E}-01$ & ${ }^{*} \mathrm{C}$ & $-1.688 E+00$ & ${ }^{*} \mathrm{C}$ & 1.761E-02 & ${ }^{*} \mathrm{C}$ & $-3.224 \mathrm{E}-01$ & ${ }^{*} \mathrm{C}$ \\
\hline 4.892E-02 & ${ }^{*} \mathrm{D}$ & $-5.170 \mathrm{E}-01$ & ${ }^{*} \mathrm{D}$ & $5.765 \mathrm{E}-03$ & ${ }^{*} \mathrm{D}$ & $-9.549 \mathrm{E}-02$ & ${ }^{*} \mathrm{D}$ \\
\hline $2.172 \mathrm{E}-02$ & ${ }^{*} \mathrm{E}$ & $-1.208 \mathrm{E}-02$ & ${ }^{*} \mathrm{E}$ & 3.197E-03 & ${ }^{*} \mathrm{E}$ & $-9.387 E-03$ & ${ }^{*} \mathrm{E}$ \\
\hline $5.852 \mathrm{E}-03$ & ${ }^{*} A * B$ & $-7.487 \mathrm{E}-02$ & ${ }^{*} A * B$ & 7.959E-04 & ${ }^{*} A$ * $B$ & $-1.309 E-02$ & ${ }^{*} A * B$ \\
\hline$-1.168 \mathrm{E}-02$ & ${ }^{*} A * E$ & $9.933 \mathrm{E}-02$ & ${ }^{*} A{ }^{*} E$ & $-1.210 \mathrm{E}-03$ & ${ }^{*} A * E$ & 2.023E-02 & ${ }^{*} A * E$ \\
\hline $1.386 \mathrm{E}-02$ & ${ }^{*} \mathrm{~B} * \mathrm{C}$ & $-1.373 \mathrm{E}-01$ & ${ }^{*} \mathrm{~B}{ }^{*} \mathrm{C}$ & $1.558 \mathrm{E}-03$ & ${ }^{*} \mathrm{~B}{ }^{*} \mathrm{C}$ & $-2.661 \mathrm{E}-02$ & ${ }^{*} \mathrm{~B} * \mathrm{C}$ \\
\hline$-8.176 \mathrm{E}-03$ & ${ }^{*} B * D$ & 8.054E-02 & ${ }^{*} B * D$ & $-9.214 \mathrm{E}-04$ & ${ }^{*} B * D$ & $1.476 \mathrm{E}-02$ & ${ }^{*} B * D$ \\
\hline 8.376E-03 & ${ }^{*} C * D$ & $-7.797 \mathrm{E}-02$ & ${ }^{*} C * D$ & 8.947E-04 & ${ }^{*} C * D$ & $-1.517 \mathrm{E}-02$ & ${ }^{*} C{ }^{*} D$ \\
\hline$-8.135 E-03$ & ${ }^{*} D * E$ & $9.299 \mathrm{E}-02$ & ${ }^{*} D * E$ & $-1.029 \mathrm{E}-03$ & ${ }^{*} D * E$ & $1.690 \mathrm{E}-02$ & ${ }^{*} D * E$ \\
\hline $1.215 \mathrm{E}-02$ & ${ }^{*} A^{\wedge} 2$ & $-1.112 \mathrm{E}-01$ & ${ }^{*} A^{\wedge} 2$ & $1.544 \mathrm{E}-03$ & ${ }^{*} A^{\wedge} 2$ & $-2.066 \mathrm{E}-02$ & ${ }^{*} A^{\wedge} 2$ \\
\hline 8.037E-03 & ${ }^{*} \mathrm{~B}^{\wedge} 2$ & $-3.725 E-02$ & ${ }^{*} \mathrm{~B}^{\wedge} 2$ & 7.871E-04 & ${ }^{*} B^{\wedge} 2$ & $-1.030 \mathrm{E}-02$ & ${ }^{*} \mathrm{~B}^{\wedge} 2$ \\
\hline 4.221E-02 & ${ }^{*} \mathrm{C}^{\wedge} 2$ & $-4.648 \mathrm{E}-01$ & ${ }^{*} \mathrm{C}^{\wedge} 2$ & 5.321E-03 & ${ }^{*} \mathrm{C}^{\wedge} 2$ & $-8.230 \mathrm{E}-02$ & ${ }^{*} \mathrm{C}^{\wedge} 2$ \\
\hline$-2.091 \mathrm{E}-02$ & ${ }^{*} D^{\wedge} 2$ & $2.596 \mathrm{E}-01$ & ${ }^{*} D^{\wedge} 2$ & $-2.553 E-03$ & ${ }^{*} D^{\wedge} 2$ & 4.557E-02 & ${ }^{*} \mathrm{D}^{\wedge} 2$ \\
\hline$-5.023 \mathrm{E}-02$ & ${ }^{*} E^{\wedge} 2$ & 3.979E-01 & ${ }^{*} E^{\wedge} 2$ & $-5.770 \mathrm{E}-03$ & ${ }^{*} E^{\wedge} 2$ & $8.170 \mathrm{E}-02$ & ${ }^{*} E^{\wedge} 2$ \\
\hline$-3.757 E-02$ & ${ }^{*} A^{\wedge} 3$ & 4.459E-01 & ${ }^{*} A^{\wedge} 3$ & $-4.995 \mathrm{E}-03$ & ${ }^{*} A^{\wedge} 3$ & 7.620E-02 & ${ }^{*} A^{\wedge} 3$ \\
\hline$-2.540 \mathrm{E}-02$ & ${ }^{*} B^{\wedge} 3$ & $2.616 \mathrm{E}-01$ & ${ }^{*} B^{\wedge} 3$ & $-2.786 \mathrm{E}-03$ & ${ }^{*} B^{\wedge} 3$ & $5.075 \mathrm{E}-02$ & ${ }^{*} \mathrm{~B}^{\wedge} 3$ \\
\hline$-5.476 \mathrm{E}-02$ & ${ }^{*} \mathrm{C}^{\wedge} 3$ & $5.415 \mathrm{E}-01$ & ${ }^{*} \mathrm{C}^{\wedge} 3$ & $-6.311 E-03$ & ${ }^{*} C^{\wedge} 3$ & $1.038 \mathrm{E}-01$ & ${ }^{*} \mathrm{C}^{\wedge} 3$ \\
\hline$-4.631 E-02$ & ${ }^{*} D^{\wedge} 3$ & $4.968 \mathrm{E}-01$ & ${ }^{*} D^{\wedge} 3$ & $-5.529 E-03$ & ${ }^{*} D^{\wedge} 3$ & 9.133E-02 & ${ }^{*} D^{\wedge} 3$ \\
\hline
\end{tabular}

\section{Conclusions}

Poor prediction of aircraft stability derivatives is often caused by unsteady, nonlinear aerodynamics brought on by high angle-of-attack and/or high angular rate maneuvers. Consequently, researchers have begun to use unsteady nonlinear modeling methodologies and forced oscillation wind tunnel testing in attempts to estimate dynamic stability derivatives.

There have been measurement data inconsistencies noted by researchers. The inconsistencies are possibly from low accuracy and non-physical values of parameter estimation. Other sources of error are due to model structure error in the form of measurement bias. Bias errors are a particular concern because the aerodynamic phenomena are occurring below $10 \mathrm{~Hz}$, which can interact with the test rig dynamics. Other sources of error not considered here include those inherent to all wind tunnel testing such as Reynolds number scaling, dynamic scaling, differences in turbulence intensity (transition), proximity to supports or tunnel boundaries. It should be noted that this study is only a foundation upon which to build. Many other sources of error may be considered, for example the force balance dynamics were not included in the study.

This study showed variability in the responses in keeping with a system that is highly nonlinear. Responses were highly sensitive to the factors (i.e. $\mathrm{J}_{\mathrm{eq}}, \mathrm{B}_{\mathrm{eq}}, \mathrm{k}$, IS, BL). In addition, and unfortunately, the nonlinear behavior of the dynamic system and its systematic biases has a coupling effect with the aerodynamics of an aircraft model (in this case the F-16XL). While factors may not change over the ranges chosen for this study in every facility, it is highly likely that similar factors will affect the results from forced oscillation testing. 


\section{Appendix}

\section{Monte Carlo Simulation Based on Taylor Series Expansion:}

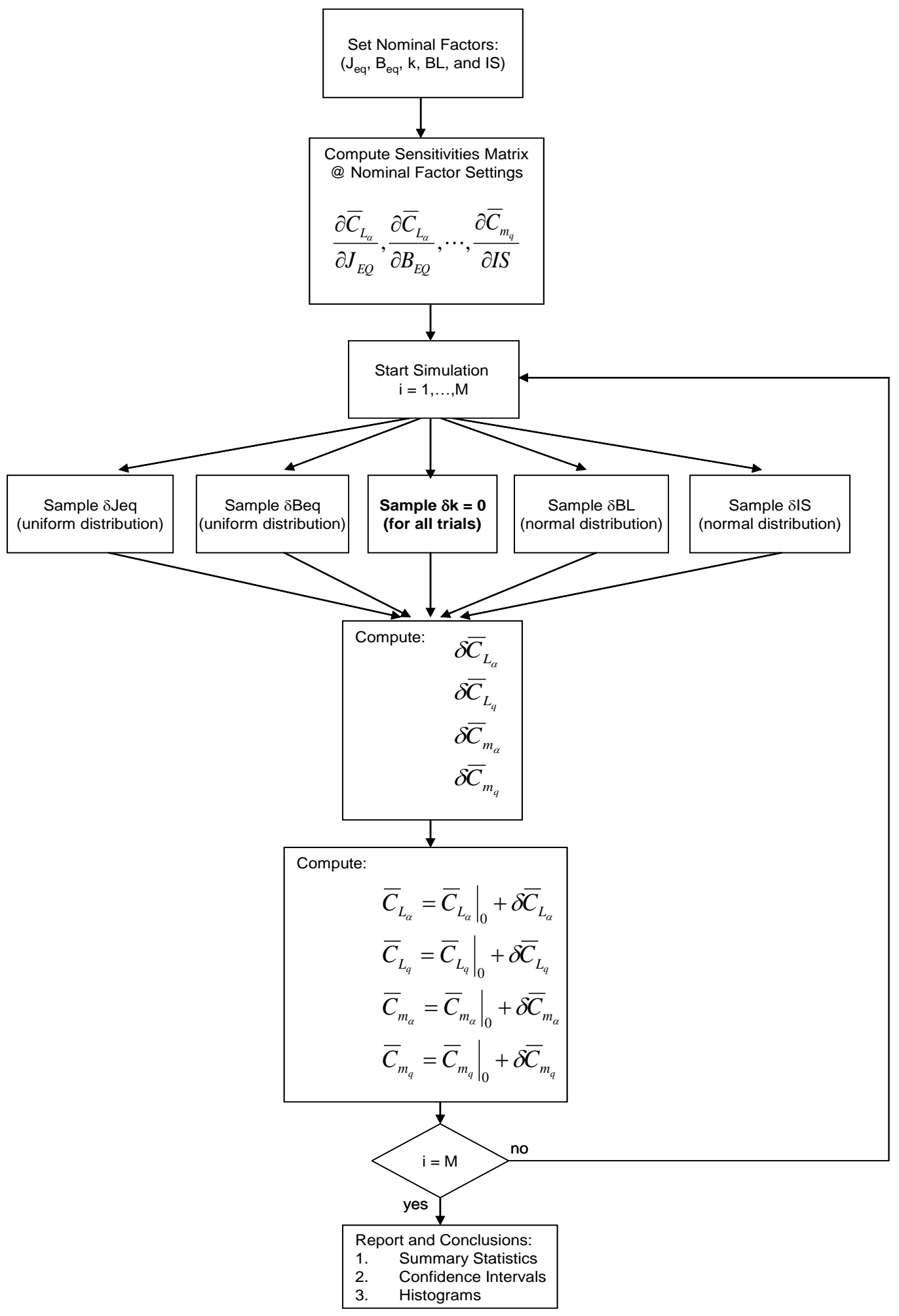

American Institute of Aeronautics and Astronautics 


\section{Monte Carlo Simulation Based on Regression Metamodels:}

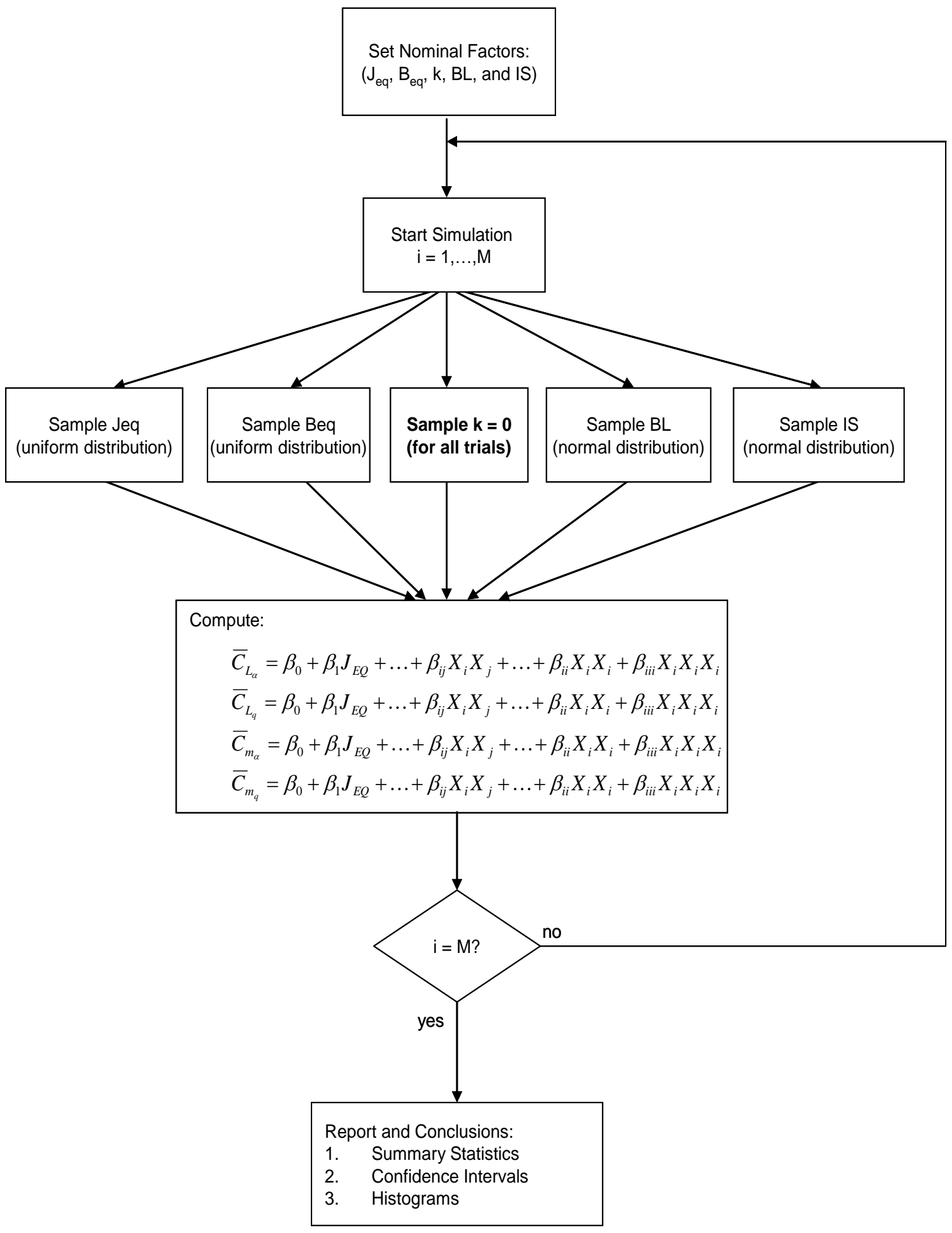




\section{References}

${ }^{1}$ Kyle, H., Lowenburg, M., and Greenwell, D., "Comparative Evaluation of Unsteady Aerodynamic Modeling Approaches," AIAA Paper 2004-5272, Aug. 2004.

${ }^{2}$ Greewell, D.I., "A Review of Unsteady Aerodynamic Modelling for Flight Dynamics of Maneuverable Aircraft," AIAA Paper 2004-5276, Aug. 2004.

${ }^{3}$ Owens, D.B., Brandon, J.M., Croom, M.A., Fremaux, C.M., Heim, E.H., and Vicroy, D.D., “Overview of Dynamic Test Techniques for Flight Dynamics Research at NASA LaRC (Invited)," AIAA Paper 2006-3146, June. 2006.

${ }^{4}$ Tomek, D.M., Sewall, W.G., Mason, S.E., and Szchur, B.W.A., "The Next Generation of High-Speed Dynamic Stability Wind Tunnel Testing (Invited)," AIAA Paper 2003-3148, June. 2006.

${ }^{5}$ Beyers, M.E., "Interpretation of Experimental High-Alpha Aerodynamics - Implications for Flight Prediction," Journal of Aircraft, Vol. 32, No. 2, March -April 1995, pp.247-261.

${ }^{6}$ Ericsson, L.E., and Reding, J.P., "Review of Support Interference in Dynamic Tests," AIAA Journal, Vol. 21, No. 12, March 1983, pp. 1652-1666.

7 Taylor, G.S., Gursul, I., and Greenwell, D.I., "Investigation of Support Interference in High-Angle-of-Attack Testing," Journal of Aircraft, Vol. 40, No. 1, Jan-Feb. 2003.

${ }^{8}$ Acum, W.E.A., "Interference Effects in Unsteady Experiments," AGARDograph 109, Oct. 1966.

${ }^{9}$ Beyers, M.E., "Unsteady Wind-Tunnel Interference in Aircraft Dynamic Experiments," Journal of Aircraft, Vol. 29, No. 6, 1992, pp. 1122-1129.

${ }^{10}$ Beyers, M.E., and Ericsson, L.E., "Ground Facility Interferences on Aircraft Configurations with Separated Flow," Journal of Aircraft, Vol. 30, No. 5, 1993, pp. 682-688.

${ }^{11}$ Polhamus, E.C., "A Review of Some Reynolds Number Effects Related to Bodies at High Angles of Attack," NASA-CR3809, Aug. 1984.

${ }^{12}$ Barlow, J.B., Rae, W.H., and Pope, A., Low-Speed Wind Tunnel Testing, John Wiley \& Sons, New York, 1999.

${ }^{13}$ Beyers, M.E., "Influence of Support Oscillation in Dynamic Stability Tests," Journal of Aircraft, Vol. 25, No. 2, Dec. 1983.

${ }^{14}$ Hanff, E.S., "Direct Forced-Oscillation Techniques for the Determination of Stability Derivatives in the Wind Tunnel,"AGARD-LS-114, 1981.

${ }^{15}$ Chambers, J.R., and Grafton, S.B., "Static and Dynamic Longitudinal Stability Derivatives of a Powered 1/9-Scale Model of a Tilt-Wing V/STOL Transport," NASA-TN-D-3591, Sept 1966.

${ }^{16}$ Freeman, D.C., Grafton, S.B., and D'Amato, R., "Static and Dynamic Stability Derivatives of a Model of Jet Transport Equipped with External-Flow Jet-Augmented Flaps," NASA-TN-D-5408, Sept 1969.

${ }^{17}$ Trieu, B.C., Tyler, T.R., Stewart, B.K., Charnock, J.K., Fisher, D.W., Heim, E.H., Brandon, J., and Grafton, S.B., "Development of a Forced Oscillation System for Measuring Dynamic Derivatives of Fluidic Vehicles," $38^{\text {th }}$ Aerospace Mechanisms Symposium, Langley Research Center, May 2006, pp. 387-399.

${ }^{18}$ Klein, V., and Murphy, P.C., "Estimation of Aircraft Unsteady Aerodynamic Parameters from Dynamic Wind Tunnel Testing," AIAA Paper 2001-4016.

${ }^{19}$ Landman, D., Simpson, J., Mariani, R., Ortiz, F., and Britcher, C., "Hybrid Design for Aircraft Wind-Tunnel Testing using Response Surface Methodolgies," Journal of Aircraft, Vol. 44, No. 4, July-Aug. 2007.

${ }^{20}$ Myers, R.H., and Montgomery, D.C., Response Surface Methodology: Process and Product Optimization using Designed Experiments, $2^{\text {nd }}$ ed., Wiley-Interscience Publication, New Jersey, 2002.

${ }^{21}$ Data Sheet, "Speed Reducer Backlash" Peerless-Winsmith Inc [online], pp. 230-231, www.winsmith.com

${ }^{22}$ Kim, S., Murphy, P.C., and Klein, V., "Evaluation and Analysis of F-16XL Wind Tunnel Data from Dynamic Tests," AIAA Paper 2003-5396, Aug., 2003.

23 Barton, R.R., "Metamodels for Simulation Input-Output Relations," Proceedings of the 1992 Winter Simulation Conference, IEEE, 1992, pp. 289-299.

${ }^{24}$ Barton, R.R., "Metamodeling: A State of the Art Review," Proceedings of the 1994 Winter Simulation Conference, IEEE, 1994, pp. 237-244.

${ }^{25}$ Simpson, T.W., Peplinski, J.D., Koch, P.N., and Allen J.K., "On the use of Statistics in Design and the Implications for Deterministic Computer Experiments,” 1997 ASME Design Engineering Technical Conferences, Sept. 1997.

${ }^{26}$ Montgomery, D.C., Peck, E.A., and Vining, G.G., Introduction to Linear Regression Analysis, $3^{\text {rd }}$ ed., John Wiley \& Son, New York, 2001.

${ }^{27}$ Sacks, J., Schiller, S.B., and Welch, W.J., "Designs for Computer Experiments," Technometrics, Vol. 31, No. 1, Feb. 1989.

${ }^{28}$ Kleijnen, J.P.C., "Statistics and Deterministic Simulation Models: Why Not?," Proceedings of the 1990 Winter Simulation Conference, IEEE, 1990, pp. 344-346

${ }^{29}$ Snee, R.D., "Validation of Regression Models: Methods and Examples," Technometrics, Vol. 19, No. 4, Nov. 1977, pp. 415-428.

${ }^{30}$ Williams, B.Y., "The Effect of Systematic Error in Forced Oscillation Wind Tunnel Test Apparatuses on Determining Nonlinear Unsteady Aerodynamic Stability Derivatives," PhD Dissertation, Aerospace Engineering Dept., Old Dominion Univ., Norfolk, VA, 2010.

${ }^{31}$ Coleman, H.W., and Steele, W.G., Experimentation, Validation, and Uncertainty Analysis for Engineers, $3^{\text {rd }}$ ed., John Wiley \& Sons, New York, 2009.

${ }^{32}$ Montgomery, D.C., Design and Analysis of Experiments, $6^{\text {th }}$ ed. Wiley \& Sons, New York, 2005. 